\title{
Research on Thunderstorm Forecasting in Fuxin, China Based on Physical Diagnostic Parameters
}

\author{
Xu Zhang, Baoli Sun, Ke Sun, Ji Liu, Xiaotong Yang, Jianing Bai, Hongjie Shi, Yuan Xie \\ Fuxin Meteorological Bureau, Fuxin, China \\ Email: zxu521@126.com
}

How to cite this paper: Zhang, X., Sun, B. L., Sun, K., Liu, J., Yang, X. T., Bai, J. N., Shi, H. J., \& Xie, Y. (2019). Research on Thunderstorm Forecasting in Fuxin, China Based on Physical Diagnostic Parameters. Journal of Geoscience and Environment Protection, 7, 106-114.

https://doi.org/10.4236/gep.2019.76009

Received: March 26, 2019

Accepted: June 24, 2019

Published: June 27, 2019

Copyright $\odot 2019$ by author(s) and Scientific Research Publishing Inc. This work is licensed under the Creative Commons Attribution International License (CC BY 4.0).

http://creativecommons.org/licenses/by/4.0/

cC) (i) Open Access

\begin{abstract}
Thunderstorms are very spectacular super-long-range discharge processes in the atmosphere, which can cause tremendous damage in an instant, often leading to casualties, resulting in damage to buildings, power supply systems, communication equipment and forest fires, causing major economic losses. In order to successfully predict thunderstorms, and many economic losses can be avoided. Using the observation data of two county stations in Yimeng County and Zhangwu County from June to August 2009-2015, 40 typical thunderstorm weather processes were selected, and 15 convective parameters related to thunderstorm activities were calculated. After statistical analysis, there are seven convective parameters with significant correlation with thunderstorm activity: convective affective potential energy (CAPE), $850 \mathrm{hPa}$ specific humidity, $700 \mathrm{hPa}$ specific humidity, $850 \mathrm{hPa}$ false equivalent temperature, maximum rising speed, strong weather threat index (SWEAT) and zero degree height $(\mathrm{ZH})$, and the correlation is greater than 0.3 . We determined the forecast threshold of the above forecasting factors, calculated the fitting rate and conducted a test report. We used the pup product to establish a short-term proximity indicator for thunderstorm warning. Three products with combined reflectivity, vertical integrated liquid water content and echo top height were selected as warning indicators for thunderstorms. The above research results were used to forecast the thunderstorm weather from June to August in the year of 2015 and 2016. The forecast accuracy rate is more than $85 \%$. In summary, the above methods have reference value and indicative significance for the forecast and warning of thunderstorm weather in Fuxin City, China.
\end{abstract}

\section{Keywords}

Thunderstorm, Forecast and Warning, Physical Parameters, Fuxin City 


\section{Introduction}

Thunderstorms are very spectacular ultra-long-distance discharge processes in the atmosphere. Due to their strong current, high temperature, strong electromagnetic radiation and other physical benefits, they can cause tremendous damage in an instant, causing thunderstorms. It often leads to casualties, which cause buildings, power supply systems, communication equipment, forest fires, storage, oil fields, etc. to burn or even explode, causing major economic losses and adverse social impacts. China is a country with many thunderstorms. The successful forecast of thunderstorms can avoid many unnecessary economic losses. In recent years, scholars in China have done a lot of research work on the potential forecast of thunderstorms. Wang et al. (2014) gave a detailed explanation and in-depth discussion on the three elements of thunderstorms in their application in forecasting and some confusing concepts. Kong et al. (2016) introduced the weather intensity index for the weather situation of thunderstorms in the northwest region, and carried out the weather-type automatic identification method of thunderstorms. On this basis, the diagnostic analysis of thunderstorm physical quantities was carried out, and the forecasting effect was better. Yu et al. (2016) selected the convective parameters with good correlation with thunderstorm as the forecasting factor, and established the thunderstorm potential prediction equation by multiple linear regression method. The equation passed the significance level test of $\alpha=0.05$. Hu et al. (2015) used the multi-parameter weighted weighting method to establish the thunderstorm potential prediction model, and combined with the mesoscale forecasting model to make the thunderstorm landing area forecast. Zhou et al. (2016) used the strong convection parameters of the Global Forecasting System (GFS) model as a predictor, and established a four-type prediction model for disaster-causing thunderstorms using the Logistic regression method. Zhang et al. (2010) used Zhengzhou station sounding data to calculate environmental parameters such as strong weather threat index, and pointed out that single environmental parameters have correlation with thunderstorm activities within a certain range of values. More comprehensive global literature review also shows how thunderstorm forecast occur. Due to inadequate radar network in India, satellite plays the dominant role for now-cast of these thunderstorms (Goyal et al., 2017). A thunderstorm forecast model is developed from an adaptive neural-fuzzy inference system to become an early warning of convective system in Malaysian and the Global Positioning System (GPS) data are as inputs to the model and evaluate its performance in predicting thunderstorm (Suparta et al., 2017). The MRL-5 weather radar and LS8000 lightning detection system are used in the observation and forecast of the development of a high-depth thunder-hail storm in Russia (Mikhailovskii et al., 2017).

The above research work has confirmed that the use of atmospheric instability parameters can predict the thunderstorm to a certain extent. These similar works on the potential forecast of thunderstorms but did not shed much light on 
the differences. However, the single atmospheric instability parameter can not fully reflect the characteristics of thunderstorm activity. The integration of multiple atmospheric instability parameters can reflect the characteristics of thunderstorm activity to some extent. Due to the complex topographical features and the different climates in China, the correlation between thunderstorm activity and convective parameters also varies in different regions. Therefore, original contributions of the present work are to analyze the correlation between atmospheric stability parameters and thunderstorm activities for different needs of different regions, which is necessary for thunderstorm activities in the forecast area.

\section{Data and Forecast Factors Selection}

\subsection{Thunderstorm Activity Characteristics}

Fuxin is located in the northwestern part of Liaoning Province, China. The whole area has a long rectangular shape, and the central axis is obliquely intersected at the intersection of $42^{\circ} 10^{\prime} \mathrm{N}$ and $122^{\circ} 00^{\prime} \mathrm{E}$. There are many low hills and hills in the whole territory, and the terrain is more complicated. The thunderstorm distribution also shows the obvious regional characteristics of Xiduodong (Zhang et al., 2016). The new thunderstorms are mainly concentrated in June-August, and the thunderstorms are the most in June, mostly concentrated in the afternoon to night (Figure 1). Because the current forecast of thunderstorms in Fuxin City mainly relies on the subjective analysis of forecasters, there is a lack of objective and quantitative forecasting methods and corresponding threshold support. Therefore, this paper uses the observation data of Yimeng County and Zhangwu County to analyze the correlation between convective parameters and thunderstorm activities based on the local climate background, and establishes the threshold of local thunderstorm forecasting and warning, which provides support and basis for thunderstorm forecasting.

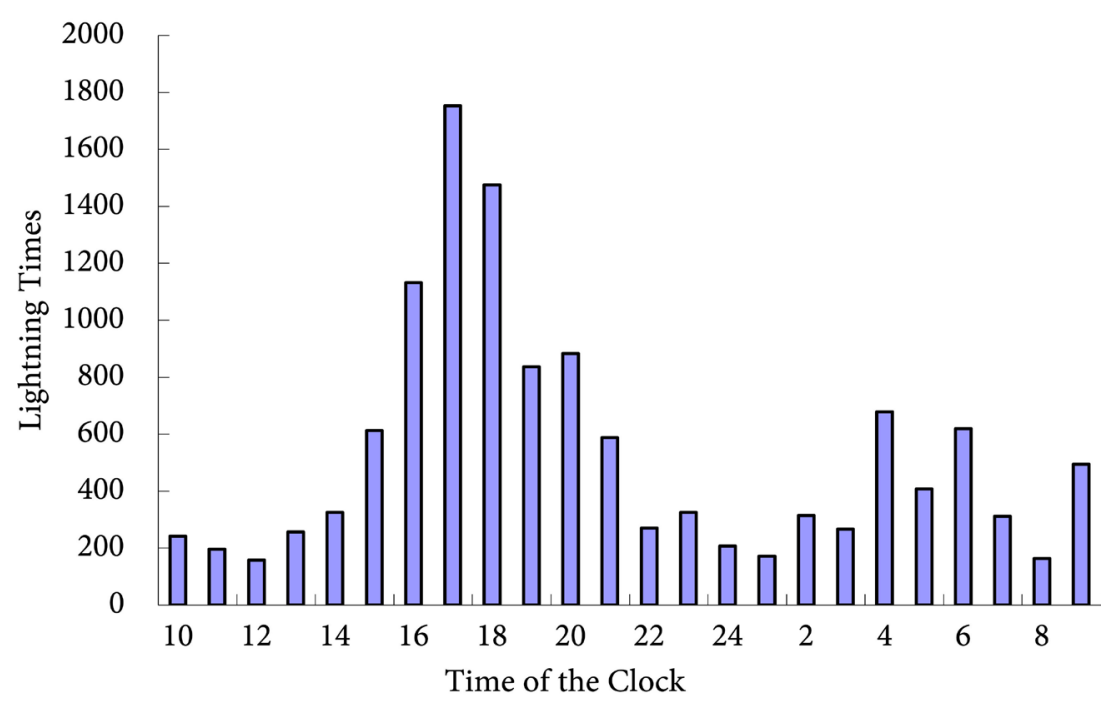

Figure 1. Diurnal variation of lightning frequency in Fuxin area (Beijing Time). 


\subsection{Parameter Selection}

At this stage, for forecasting thunderstorms and the resulting strong convective weather, China mainly uses short-term forecasting based on live observation data, including radar and satellite sounding data (Li et al., 2004). For a longer time forecast, it mainly depends on the forecaster's experience in forecasting and forecasting the weather situation. If the forecast of thunderstorm is still difficult to choose, a quantitative and objective thunderstorm forecasting model is needed as a reference for forecasting (Liu et al., 2010). The choice of forecast parameters is based on the following three conditions: the instability of the stratification, the water vapor conditions and the appropriate trigger factors. The relevant physical parameters are calculated using the observation data at 08:00 and 20:00 (Beijing time, the same below). If these parameters reach a certain threshold range, then this potential thunderstorm can be predicted. This paper selects K index, Sabour index (SI), convective affective potential energy (CAPE), lift index (LI), temperature difference of 850 - $500 \mathrm{hPa}$, false equivalent temperature of $850 \mathrm{hPa}$, specific humidity of $850 \mathrm{hPa}$, etc. (see Table 1) Characterizes the parameters of atmospheric instability and water vapor conditions, and obtains the single correlation coefficient of each station's parameters and thunderstorms. According to the correlation between the parameters and the occurrence of thunderstorms in Fuxin area, and considering the representative meaning of each parameter in terms of dynamics and thermodynamics, according to the principle of non-reproducibility of forecasting factors, we remove those factors with similar physical meanings and select from 14 parameters. The forecasting factors for the better prediction of the new thunderstorm potential are the convective affective potential energy (CAPE), $\mathrm{K}$ index, lift index (LI), $850 \mathrm{hPa}$ specific humidity, $850 \mathrm{hPa}$ and $500 \mathrm{hPa}$ temperature difference, and the total index (TT). Specific analysis (Table 1) shows the correlation coefficients between representative parameters and the occurrence of thunderstorms.

It can be seen from Table 1 that the CAPE, $850 \mathrm{hPa}$ specific humidity, 700 $\mathrm{hPa}$ specific humidity, $850 \mathrm{hPa}$ false equivalent temperature, maximum rising speed, SWEAT and $\mathrm{ZH}$ are all shown good correlation. The correlation coefficient is also above 0.3 , and the correlation coefficient of CAPE and $850 \mathrm{hPa}$

Table 1. Convection parameters related to thunderstorm activities and its correlation coefficients.

\begin{tabular}{cccc}
\hline Convection Parameters & Correlation Coefficients & Convection Parameters & Correlation Coefficients \\
\hline Convective Affective Potential Energy (CAPE) & 0.501 & Strong Weather Threat Index (SWEAT) & 0.255 \\
Convective Inhibition (CIN) & -0.066 & Maximum Rising Speed & 0.457 \\
Energy Helicity (EHI) & 0.289 & $850 \mathrm{hPa}$ and $500 \mathrm{hPa}$ Temperature Difference & -0.055 \\
Lifting index (LI) & 0.388 & $850 \mathrm{hPa}$ False Equivalent Temperature & 0.380 \\
$850 \mathrm{hPa}$ Specific Humidity & 0.625 & Zero Degree Layer Height (ZH) & 0.315 \\
$700 \mathrm{hPa}$ Specific Humidity & 0.513 & Total Index (TT) & 0.249 \\
$500 \mathrm{hPa}$ Specific Humidity & 0.233 & K index & 0.045 \\
\hline
\end{tabular}


specific humidity is greater than 0.5 , respectively. It can be seen that the prediction of thunderstorms has a good guiding significance.

\section{Threshold Selection}

The typical thunderstorm weather process with 1 - 2 hours from June to August in 2009-2015 was selected. According to the selected six parameters, the NCEP reanalysis data was used to calculate the physical quantities by the GrADS software at 8,14 or 20 o'clock, which is the value of the most recent time before the thunderstorm, the following environmental field element values and fitting rate are obtained (see Table 2).

CAPE is the work of the air block accumulated by the positive buoyancy between the free convection height and the equilibrium height. It reflects the magnitude of the unstable energy, which involves both the unstable strength and the depth of convective development. The CAPE value The bigger the more likely it is to produce thunderstorms. In the selected samples, the CAPE value is greater than $600 \mathrm{~J} \cdot \mathrm{kg}^{-1}$ with a fitting rate of $90 \%$, the smallest CAPE value is $423 \mathrm{~J} \cdot \mathrm{kg}^{-1}$, and the maximum is $3159 \mathrm{~J} \cdot \mathrm{kg}^{-1}$. The lift index (LI) is an index indicating convective instability. It indicates that a gas block starts from the ground and rises along the adiabatic heat to the elevated condensate height, and then rises to a temperature of $500 \mathrm{hPa}$ along the wet adiabatic line. The difference obtained by subtracting the actual atmospheric temperature. When the difference is positive, it means that the atmosphere is stable. When the value of LI is negative, and the negative value is larger, the higher the CAPE, the more unstable the gas layer. The value of LI from -1 to -3 indicates instability, -4 to -6 indicates very unstable, and -7 or less indicates extreme instability. Analysis of the sample found that the fitting rate of $\mathrm{LI} \leq-3$ is $80 \%$, which can be used as a predictor of thunderstorms. Specific humidity can reflect the water vapor condition of the lower atmosphere very well. $92.5 \%$ of the thunderstorms occur in the case of $q \geq 6$. It can be seen that the low-level water vapor plays a decisive role in the occurrence of thunderstorms. The total index TT $=\mathrm{T} 850+\mathrm{Td} 850-2 \mathrm{~T} 500$, the larger the TT, the more unstable it is, only one case is 37 , the rest are above 39 , and the fitting rate is $97.5 \%$. The temperature difference T850-500 is a good parameter for thermal instability, of which 5 cases are below 25 degrees and the rest are above

Table 2. Threshold for convection parameters.

\begin{tabular}{ccc}
\hline Convection Parameters & Threshold & Fitting Rate (\%) \\
\hline Convective Affective Potential Energy (CAPE) ${\mathrm{J} \cdot \mathrm{kg}^{-1}}^{-}$ & $\mathrm{CAPE} \geq 600$ & 90 \\
Lifting Index (LI) ${ }^{\circ} \mathrm{C}$ & $\mathrm{LI} \leq-3$ & 80 \\
$850 \mathrm{hPa}$ Specific Humidity $\left(\mathrm{q}_{850}\right){\mathrm{g} \cdot \mathrm{kg}^{-1}}^{\text {Total Index }(\mathrm{TT}){ }^{\circ} \mathrm{C}}$ & $\mathrm{q}_{850} \geq 6$ & 92.5 \\
Temperature Difference $\left(\mathrm{T}_{850-500}\right){ }^{\circ} \mathrm{C}$ & $\mathrm{TT} \geq 39$ & 97.5 \\
$\mathrm{~K}$ index $(\mathrm{K}){ }^{\circ} \mathrm{C}$ & $\mathrm{T}_{850-500} \geq 25$ & 87.5 \\
\hline
\end{tabular}


25 degrees. The $\mathrm{K}$ index is a comprehensive feature of temperature and humidity. The fitting rate of $\geq 28$ at $08: 00$ and $\geq 32$ at noon is $74.35 \%$. The above six physical indicators all satisfied the sample accounted for $42.5 \%$; the sample that satisfies the four conditions accounted for $95 \%$, of which the $\mathrm{K}$ index did not meet the conditions accounted for $21.1 \%$, the T850-500 did not meet the $25^{\circ} \mathrm{C}$ accounted for $13.2 \%$, the uplift index LI Unsatisfied accounts for $15.8 \%$, convective effective potential energy CAPE and specific humidity $\mathrm{q}$ are not satisfied $5.3 \%$. In summary, when doing short-term forecasting, comprehensively analyze the physical quantities according to numerical predictions such as WRF, T639 and EC-thin. The environmental field indicators of thunderstorms in Fuxin area should meet at least the first four points in Table 2, and the future $24-72$ hours of thunderstorms can be predicted.

\section{Short-Term Warning of Thunderstorms}

Using the radar products of Yingkou City, Liaoning Province, for short-term nowcasting, select the thunderstorms in Fuxin area (Yimeng County or Zhangwu County), and 19 thunderstorm days with a duration of 1 - 2 hours as samples to study the thunderstorm-intensive area radar's echo characteristics. It has been found that the echo intensity above $35 \mathrm{dBZ}$ is the intensity that can be achieved by most of the more vigorous monomers, and the echo of this intensity is comparable to non-Thunderstorm cells in terms of time, duration and height. The obvious difference is thus a better radar characteristic parameter that distinguishes between thunderstorms and non-thunderstorms. The height of echo development is a very important prerequisite for the generation of lightning. Without the development of a high cloud top, there is no condition for generating a large number of ice phase particles and a mechanism for the electrification of net charge separation. It can be seen from the thunderstorm distribution density map (omitted) that it corresponds to the echo top height and thunderstorm area, with an average of more than $8 \mathrm{~km}$ and a maximum of $14-15 \mathrm{~km}$. Vertically accumulating liquid water means converting the reflectance factor data to an equivalent liquid water value, so the large VIL just reflects the larger precipitation particles in the cloud. These areas are often also places where convection develops vigorously, with strong vertical ascent movements and sufficient water vapor. In general, VIL can be used as an early warning indicator for hail. It has good guiding significance. As another auxiliary factor for thunderstorm warning, the threshold value is lower than that of hail, and $10 \mathrm{~kg} / \mathrm{m}^{2}$ is selected. Therefore, in summary, $\mathrm{CR} \geq 35 \mathrm{Dbz}$ (fitting rate: $89.5 \%$ ) $\mathrm{ET} \geq 8 \mathrm{~km}$ (fitting rate: $89.5 \%$ ) VIL $\geq 10 \mathrm{~kg} / \mathrm{m}^{2}$ (fitting rate: $84.2 \%$ ) is selected as a short-term warning indicator for lightning. If there is a thunderstorm in the short-term forecast, the forecaster will closely monitor the occurrence and trend of the thunderstorm detected by the lightning locator 2 - 3 hours before the thunderstorm occurs. If the new echo has developed to $30 \mathrm{dBZ}$ or has the same intensity or even stronger, the echoes will be closely monitored and released with warning 
information when entering the new territory. Simultaneous monitoring of the lightning locator and radar echo can facilitate the forecaster to perform fixed-point, timed tracking services.

\section{Application}

The research results were tested and reported in thunderstorm weather in $\mathrm{Au}$ gust 2015 and June-August 2016. The WRF, T639 and EC-thin numerical forecast products were used for short-term forecast. The date of Table 3 is the thunderstorm date, and the time is 8 and 14 o'clock forecast and environmental field characteristics.

From the short-term forecast effect, as long as the thunderstorm forecast conditions are met, we can predict thunderstorms. For a total of 20 thunderstorms, the thunderstorm accuracy rate can reach $85 \%$, the air report rate is $10 \%$, and the false negative rate is $5 \%$. From the short-term effect test, we can predict the

Table 3. Thunderstorm day environmental field characteristics.

\begin{tabular}{|c|c|c|c|c|c|c|c|c|c|c|c|c|c|c|}
\hline \multirow{3}{*}{ Date } & \multicolumn{12}{|c|}{ Environmental Field Characteristics } & \multirow{3}{*}{ Forecast } & \multirow{3}{*}{ Occur } \\
\hline & \multicolumn{2}{|c|}{ CAPE } & \multicolumn{2}{|c|}{$\mathrm{q}$} & \multicolumn{2}{|c|}{$\mathrm{Li}$} & \multicolumn{2}{|c|}{ T850-500 } & \multicolumn{2}{|c|}{$\mathrm{K}$} & \multicolumn{2}{|c|}{$\mathrm{TT}$} & & \\
\hline & 08 & 14 & 08 & 14 & 08 & 14 & 08 & 14 & 08 & 14 & 08 & 14 & & \\
\hline 2015.8 .6 & 929 & 2825 & 10 & 10 & -5 & -8 & 27 & 24 & 30 & 30 & 47 & 42 & $\mathrm{Y}$ & $\mathrm{Y}$ \\
\hline 2015.8 .7 & 1425 & 3080 & 10 & 9 & -5 & -10 & 26 & 27 & 37 & 32 & 47 & 44 & $\mathrm{Y}$ & $\mathrm{Y}$ \\
\hline 2015.8.18 & 1710 & 2883 & 8 & 8 & -5 & -11 & 28 & 27 & 28 & 25 & 47 & 48 & $\mathrm{Y}$ & $\mathrm{Y}$ \\
\hline 2015.8.19 & 2162 & 3147 & 8 & 7.5 & -8 & -12 & 30 & 30 & 29 & 28 & 48 & 49 & $\mathrm{Y}$ & $\mathrm{Y}$ \\
\hline 2015.8 .20 & 919 & 3109 & 8 & 7.5 & -3 & -11 & 27 & 29 & 32 & 29 & 48 & 48 & $\mathrm{Y}$ & $\mathrm{Y}$ \\
\hline 2015.8 .22 & 1371 & 2635 & 9 & 9.5 & -2 & -8 & 24 & 26 & 27 & 27 & 43 & 46 & $\mathrm{Y}$ & $\mathrm{Y}$ \\
\hline 2015.8 .27 & 1066 & 2141 & 6 & 7 & -4 & -5 & 26 & 24 & 23 & 25 & 42 & 39 & $\mathrm{Y}$ & $\mathrm{Y}$ \\
\hline 2016.6 .6 & 55 & 492 & 4.5 & 6 & 0 & -3 & 29 & 30 & 17 & 26 & 42 & 49 & $\mathrm{~N}$ & $\mathrm{Y}$ \\
\hline 2016.6 .9 & 151 & 1388 & 5.5 & 8.5 & 0 & -5 & 31 & 31 & 24 & 31 & 49 & 52 & $\mathrm{Y}$ & $\mathrm{Y}$ \\
\hline 2016.6 .10 & 0 & 183 & 6.5 & 8 & 4 & 0 & 27 & 28 & 23 & 28 & 43 & 47 & $\mathrm{~N}$ & $\mathrm{Y}$ \\
\hline 2016.6.12 & 807 & 1147 & 5 & 5.5 & -2 & -4 & 29 & 30 & 22 & 26 & 47 & 48 & $\mathrm{Y}$ & $\mathrm{Y}$ \\
\hline 2016.6 .18 & 646 & 787 & 6.5 & 6 & -3 & -4 & 30 & 32 & 29 & 31 & 50 & 53 & $\mathrm{Y}$ & $\mathrm{Y}$ \\
\hline 2016.6 .21 & 482 & 1567 & 9.5 & 10 & -2 & -5 & 26 & 28 & 38 & 35 & 49 & 49 & $\mathrm{Y}$ & $\mathrm{Y}$ \\
\hline 2016.6 .22 & 1476 & 2866 & 10 & 10 & -7 & -11 & 30 & 34 & 37 & 33 & 53 & 55 & $\mathrm{Y}$ & $\mathrm{Y}$ \\
\hline 2016.6 .30 & 1506 & 2482 & 9 & 9.5 & -4 & -7 & 26 & 25 & 32 & 29 & 47 & 45 & $\mathrm{Y}$ & $\mathrm{Y}$ \\
\hline 2016.7.25 & 643 & 2001 & 12 & 14 & -3 & -7 & 22 & 22 & 31 & 37 & 39 & 41 & $\mathrm{Y}$ & $\mathrm{Y}$ \\
\hline 2016.7.28 & 2168 & 2570 & 9 & 10 & -8 & -10 & 28 & 29 & 31 & 32 & 45 & 47 & $\mathrm{Y}$ & $\mathrm{Y}$ \\
\hline 2016.8 .6 & 1151 & 817 & 10 & 13 & -4 & -3 & 24 & 28 & 18 & 26 & 39 & 45 & $\mathrm{Y}$ & $\mathrm{Y}$ \\
\hline 2016.8 .12 & 624 & 303 & 8 & 10 & -3 & -2 & 27 & 28 & 31 & 34 & 42 & 44 & $\mathrm{Y}$ & $\mathrm{N}$ \\
\hline 2016.8 .18 & 545 & 581 & 12 & 12 & -2 & -1 & 24 & 21 & 33 & 32 & 43 & 39 & $\mathrm{~N}$ & $\mathrm{~N}$ \\
\hline
\end{tabular}

Notes: "Y" stands for forecasting thunderstorms and thunderstorms, and "N" stands for no forecast or occurs thunderstorms. 
occurrence of thunderstorms in the process of meeting the environmental field factor indicators and the thunderstorm warning indicators. The accuracy of the above two conditions can reach $88.8 \%$. 5.6\%, the false negative rate was $5.6 \%$.

\section{Conclusion}

We calculated the correlations of thunderstorms predictors and then selected the factors with good correlation. They are convective affective potential energy (CAPE), $850 \mathrm{hPa}$ specific humidity, $850 \mathrm{hPa}$ false equivalent temperature, maximum rising speed, strong weather threat index (SWEAT) and zero-level height (ZH). We used them as short-term predictors of thunderstorms. According to the selected factors, the screening criteria of thunderstorm forecast in summer from June to August are carried out, and the fitting rate is calculated, and the fitting effect is good. We selected radar short-term warning products meeting the following conditions: $\mathrm{CR} \geq 35 \mathrm{dBz}, \mathrm{ET} \geq 8 \mathrm{~km}$ and $\mathrm{IL} \geq 10 \mathrm{~kg} / \mathrm{m}^{2}$. The thunderstorms in August 2015 and June-August 2016 were tested and reported, and the accuracy of forecasting and warning was above $85 \%$. The application effect is better.

Thunderstorms are the main dangerous weather that affects the safety of people's lives and property in the summer of Fuxin, China, and it is also the difficulty of forecasters' weather forecast. Many of the physical quantity parameters in the T-LnP diagram analyzed by the daily forecaster are the common parameters for calculating unstable energy (Xu et al., 2011). In the future, the calculation of physical quantity parameters, combined with weather map classification, and the use of multi-factor comprehensive correlation to produce thunderstorm forecast will become the main method. For the weather type census of thunderstorm weather, the conventional weather analysis method is applied to analyze the large-scale circulation background, and the weather model is established according to the main influence system. At the same time, the physical quantity parameters are extracted, and the daily thunderstorm occurrence probability and the physical quantity parameter comparison could be automatically generated in the future.

\section{Acknowledgements}

None.

\section{Conflicts of Interest}

The authors declare no conflicts of interest regarding the publication of this paper.

\section{References}

Goyal, S., Kumar, A., Mohapatra, M., Rathore, L. S., Dube, S. K., Saxena, R. et al. (2017). Satellite-Based Technique for Nowcasting of Thunderstorms over Indian Region. Journal of Earth System Science, 126, 79-80. https://doi.org/10.1007/s12040-017-0859-2

$\mathrm{Hu}, \mathrm{X}$., Jiang, F., Xu, W. et al. (2015). Research on Thunderstorm Potential Prediction 
Method Based on Unstable Parameter Statistics. Zhejiang Meteorology, 37, 11-17.

Kong, D., Wang, J., Shang, K. et al. (2016). Diagnosis of Thunderstorm Forecasting Method in the Eastern Part of Northwest China Based on Weather Classification and Physical Quantity. Journal of Meteorology and Environment, 2, 32-39.

Li, Y., Gao, S., \& Liu, J. (2004). Study on Convective Energy Calculation and Prediction Technology of Strong Convective Weather Falling Area. Quarterly Journal of Applied Meteorology, 15, 10-20.

Liu, W., Zhuo, W., \& Yan, J. (2010). Research on Thunderstorm Forecasting Method Based on Convective Parameters. Plateau Mountain Meteorology Research, 30, 22-25.

Mikhailovskii, Y. P., Sin'kevich, A. A., Pawar, S. D., Gopalakrishnan, V., Dovgalyuk, Y. A., Veremei, N. E. et al. (2017). Investigations of the Development of Thunderstorm with Hail. Part 2. Analysis of Methods for the Forecast and Diagnosis of the Electrical Properties of Clouds. Russian Meteorology \& Hydrology, 42, 377-387. https://doi.org/10.3103/S1068373917060036

Suparta, W., Zulkeple, S. K., \& Putro, W. S. (2017). Estimation of Thunderstorm Activity in Tawau, Sabah Using GPS Data. Advanced Science Letters, 23, 1370-1373. https://doi.org/10.1166/asl.2017.8391

Wang, X., Yu, X., \& Zhou, X. (2014). Discussion on Several Basic Issues in Thunderstorm Potential Prediction. Meteorology, 40, 389-399.

$\mathrm{Xu}$, Y., Yin, L., Zhang, T. et al. (2011). Establishment and Application of Yunnan Thunderstorm Potential Prediction System. Journal of Yunnan University (Natural Science Edition), 33, 1-7.

Yu, R., Du, M., Du, J. et al. (2016). Research on Prediction Method of Thunderstorm Activity in Wuhan Based on Multi-Convection Parameters. Meteorological Science and Technology, 44, 269-274.

Zhang, X., Wang, X., Wang, Q. et al. (2010). Environmental Field Characteristics and Potential Prediction of Thunderstorms in Zhengzhou. Meteorological Monthly, 26, 95-100.

Zhang, X., Xin, Y., Shu, H. et al. (2016). Analysis and Application of Lightning Location Data in Fuxin Area. Natural Science, 2, 238.

Zhou, L., Wang, K., \& Liu, N. (2016). Study on Disaster Prediction of Disaster Caused by Disaster Based on Logistic Regression. Journal of Meteorology and Environment, 32, 147-153. 